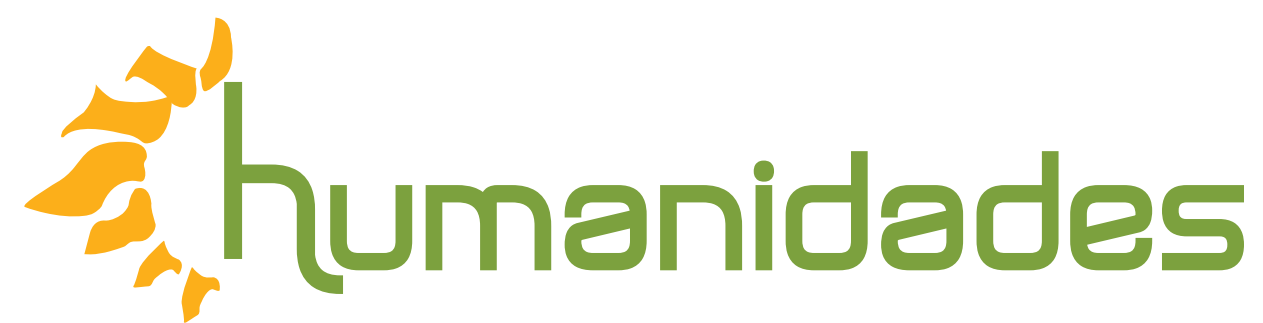

Revista humanidades

Enero-Junio, 2015 • Volumen 5, Número 1 • ISSN 2215-3934• pp. 1-18

\title{
La importancia de llamarse Lilia
}

DOI: http://dx.doi.org/10.15517/h.v5i1.19384

Recibido: 02-Marzo-2015 / Aceptado: 10-Abril-2015

\section{Teresa Fallas Arias}

Doctora, profesora Catedrática en la Sección de Comunicación y Lenguaje de la

Escuela de Estudios Generales de la Universidad de Costa Rica.

Correo electrónico: teresa.fallas@ucr.ac.cr

Más sobre el autor:

Todos los derechos reservados. Universidad de Costa Rica. Esta revista se encuentra licenciada con Creative Commons Reconocimiento-NoComercial-SinObraDerivada 3.0 Costa Rica.

Correo electrónico: humanidades.eeg@ucr.ac.cr / Sitio web: http:/ / revistas.ucr.ac.cr/index.php/humanidades 


\title{
La importancia de llamarse Lilia
}

\section{Resumen}

En esta indagación sobre la autobiografía y el curriculum operis de la escritora costarricense Lilia Ramos se vislumbra que el cambio de nombre, agenciado por Lilia desde su infancia, es una especie de conjuro con el que se autoafirma y reinventa desde niña, para resplandecer intelectual, académica y profesionalmente de adulta, cuando logra trasmutar su complejo de "fealdad" en resistencia vital. Esta lectura se realiza desde la perspectiva expuesta por Judith Butler en el libro Lenguaje, poder e identidad, texto donde la teórica se refiere a la acción violenta e injuriosa de los nombres y su relación con la propia identidad.

\section{The importance of being called Lilia}

\begin{abstract}
In this inquiry on the 'autobiografía' (autobiography) and the 'curriculum operis' of the Costa Rican writer Lilia Ramos I glimpse at the change of name scrounged by Lilia since her infancy, as a kind of incantation in which she asserts and reinvents herself since she was a little girl, to shine intellectually, academically and professionally as an adult, when she manages to transmute her 'ugliness' complex into vital resistance. I focus this reading on the perspective written by Judith Butler in the book Language, power and identity, a text in which the rhetoric refers to the violent and injurious action of names and their relationship with personal identity.
\end{abstract}

\author{
Palabras claves: \\ Literatura, identidad, \\ sujeto, complejo de fealdad, \\ resistencia.
}


Al ser llamado con un nombre insultante, uno es menospreciado y degradado. Pero [...] al ser llamado por un nombre se le ofrece a uno también, paradójicamente, una cierta posibilidad de existencia social, $[\ldots]$ la palabra ofensiva corre el riesgo de introducir al sujeto en el lenguaje, de modo que el sujeto llega a usar el lenguaje para hacer frente a este nombre ofensivo.

(Butler, 2004, p. 17)

En esta exploración de la autobiografía y el curriculum operis de la escritora costarricense Lilia Ramos, textos incluidos en el libro Fulgores en mi ocaso, se vislumbra que el cambio de nombre, agenciado por Lilia desde su infancia, es una especie de conjuro con el que se autoafirma y reinventa desde niña, para resplandecer intelectual, académica y profesionalmente de adulta, cuando logra trasmutar también su complejo de "fealdad" en resistencia vital. Esta indagación se realiza desde la perspectiva expuesta por Judith Butler en el libro Lenguaje, poder e identidad, texto donde la teórica se refiere a la acción violenta e injuriosa de los nombres y su relación con la propia identidad.

Según Butler "el sujeto no sólo es fundado por el otro, necesitando de una llamada para existir, sino que además su poder proviene de la estructura de esa llamada que es al mismo tiempo vulnerabilidad lingüística y ejercicio" (Butler, p. 57). Esto por cuanto todo sujeto entra "en el espacio social y en el tiempo al ser nombrados. El nombre que llevamos, la designación que nos confiere singularidad, depende del otro [...] Al menos esta es la comprensión general que existe acerca del nombre propio" (Butler, p. 55). Nombrados incluso antes del nacimiento, "nuestra constitución social tiene lugar sin que nos demos cuenta” (Butler, p. 58), razón por la cual podemos encontrarnos con nuestro "yo constituido por sorpresa, con 
preocupación o [...] incluso con horror" (Butler, 58), emoción experimentada y registrada por Lilia Ramos en su autobiografía, cuando relata que empezó a defender su vigorosa individualidad desde su infancia (Ramos, p. 222).

En la autogénesis del sujeto, la sujeción es constante porque al ser afirmado por la voz que lo llama, queda "siempre subordinado a la autoridad, a la que luego se somete" (Butler, 60). Según Butler "ser llamado por alguien es traumático: es un acto que precede mi voluntad, un acto que me trae al mundo lingüístico en el que podré empezar a ejercer la agencia” (Butler, 68) y para demostrar el trauma improvisa una escena en la cual quien es llamado por un nombre que le provoca sufrimiento, se gira para protestar ante la indiferencia del otro. Este acto remite a la postura de Lilia cuando, con apenas cuatro años, reniega de su nombre con desplantes melodramáticos, mientras su madre, calificada de ella de manera despectiva, se muestra indiferente a sus protestas:

Yo: No me gusta mi nombre [...]

Ella: Es el de tu abuelita y te quiere mucho.

Yo: Está bien para una vieja. Pónganme otro.

Ella: Se entristecería. Es muy desgraciada: tiene un cáncer.

Yo: Entonces, debo esperar su muerte.

Ella: ¡Por Dios! ¡No diga eso!

(Ramos, p. 222-223).

Los reclamos de Lilia acerca del cambio de nombre, son constantes e involucran su complejo de fealdad, una pesadilla recurrente, como se aprecia en otro de los fragmentos de su Autobiografía donde el padre parece aliarse a la niña: 
Yo: ... Horrible, ¡Cámbienmelo!

El: La niña tiene razón.

Ella: ... (Rostro severo)

Yo: Yo tan fea, tan pobre y con ese nombre horroroso.

Ambos se carcajearon.

(Ramos, p. 223)

Aunque Butler indica que en los formularios burocráticos el nombre interpelativo se puede dar sin hablante, por ser un territorio de poder discursivo que opera $\sin$ sujeto, es en este tipo de protocolos donde Lilia se posiciona y potencializa cuando logra liberarse del nombre que la sujeta al responder, precipitadamente, Lilia Ramos Valverde, saboteando la voz del padre, quien no tiene tiempo de reaccionar a la pregunta hecha por la maestra del kindergarden. Y es que si el nombre propio tiende a fijar, a congelar, a delimitar y a transformar en sustancia, (Butler, p. 63), paradójicamente "puede producir una respuesta inesperada que abre posibilidades" (Butler, p. 17), "para una movilización de oposición” (Butler, p. 261), pues ofrece alternativas contrarias a la ofensa y a la violencia incitadas por el nombre impuesto, debido a que ciertos actos del habla "tienen el poder [...] de desencadenar una serie de consecuencias" (Butler, p. 38), porque "lo que se dice en el habla podría prefigurar aquello que hará el cuerpo" (Butler, p. 28).

Lilia se rebela al nombre impuesto autonombrándose con "cinco letras de pura eufonía" (Calvo, p. 99), con lo cual logra reinventarse en un acto inaugural liberador, rehusando llamarse como su abuela materna, "una santa para quienes la rodeaban" (Ramos, p. 222), una vieja egoísta, enferma y amargada que simulaba ser caritativa a expensas de sus hijas, según su nieta; vieja que parece infundir en la niña el miedo a la muerte y la inseguridad acerca de su supervivencia. El cambio de nombre y su consecuente autoafirmación le permiten a Lilia desafiar otra serie 
de infortunios que la oprimen y marcan desde niña, como la carencia de recursos económicos, la muerte de su madre, el abandono-desaparición del padre sin dejar ningún rastro y el fantasma de la fealdad.

Pese a que al autonombrarse Lilia se ejercita para enfrentar el complejo de "fealdad" -corroborado cuando su madre, al aplicarle un correctivo por romper las fotografías en las que aparece su imagen, le recalca que "lo más importante en la vida es ser bueno. Y tú lo eres y lo serás siempre. Dios te regaló mucho talento y sensibilidad. Los cultivarás. La bondad y la sabiduría te harán hermosa" (Ramos, p. 221) -esta obsesión la perseguirá largo tiempo-. Pero si las palabras maternas le confirman la impresión que tiene sobre su apariencia física, también le reafirman sus virtudes espirituales, razón por la cual las valora como "el incentivo más poderoso para trasmutar mi complejo de inferioridad en realizaciones que me han brindado mucha ventura" (Ramos, p. 221). Aunque Lilia imagina su "fealdad" como una especie de minusvalía, logra convertirla en fortaleza al reconocer que "gracias a haberme aceptado tal y como los análisis -auto y ajenos- me revelaron, pude mejorar algunas fallas y a enojarme sólo por motivos trascendentales y a proceder entonces con energía" (Ramos, p. 225). ${ }^{1}$

Como expone Umberto Eco en el libro Historia de la fealdad, lo feo "siempre se ha definido por oposición a lo bello" (Eco, p. 8), por lo que es probable que Lilia percibiera su "fealdad" contrapuesta a la belleza de su madre, comparación que ahondó en ella "la sensación de menoscabo" (Ramos, p. 221), debido a que la beldad de su madre se constituyó en un arquetipo inalcanzable por ser blanca, mientras Lilia no pasará de ser mi negrita muy querida; referida así por su madre cuando alguien, "mirando alternativamente a madre y a hija y con gesto de asombro" (Ramos, p. 221), le preguntaba si la niña era suya. Aunque el diminutivo materno revela una gran ternura, no atenuó el descontento de Lilia con su físico, especialmente con su color de piel, rasgo que podría ser el causante de su malestar, 
aguijoneado por su vecina y compañera de juegos que la llamaba estafermo (adefesio) y por compartir en el colegio con Yolanda Oreamuno y Eunice Odio, mujeres consideradas muy bellas en la sociedad costarricense. ${ }^{2}$

El malestar de Lilia con su color de piel se acrecentó en Limón, provincia en la que vivió parte de su infancia y adolescencia y donde experimentó, en las prácticas sociales cotidianas, la ideología racial ${ }^{3}$; la misma ideología creadora del mito de la Costa Rica blanca donde la categoría de blanco confería estatus racial y privilegios sociales, en "contraposición con "otros" raciales denigrados" (Putnam, p. 151) como los indígenas, etnias de las que Lilia reconoce ser un buen ejemplo (Ramos, p. 37), en una época (dos primeras décadas del siglo XX) donde el color de la piel es una de las características "más relevantes para la categorización de los grupos humanos (Putnam, p. 141). ${ }^{4}$

Estudiosa de la psicología y defensora de su propia unicidad, Lilia logró trasmutar su complejo de "fealdad" enfrentándose a los paradigmas estéticos predominantes, con autoanálisis y cuando se descubre en la mirada de los otros como un ser irreductible y excepcional, frente al proceso uniformador. Desde esa perspectiva vislumbra que "es el otro, su mirada lo que nos define y nos forma" (Eco, p. 13), pues son sus amigos y compañeros de la Universidad de Columbia en Nueva York quienes reconocen el tesoro poseído por Lilia, del que ella apenas tenía conciencia:

[...] un privativo diáfano y robusto. Hasta entonces yo había creído en que esa divina merced era patrimonio de casi todo el mundo, algo así como un denominador común de la humanidad. A partir de esa época feliz empecé a actuar con más certidumbre, a vigorizar mi fe en mí misma, a sustituir la sensación de extravagancia con una de legitimidad. El hallazgo no sólo me sirvió para elevar mi autoaprecio, sino para ayudar a mi prójimo en la tarea de singularizarse [...] (Ramos, p. 225). 
De la inmersión en su propia unicidad, Lilia emerge gozosa para irradiar su talento individual y colectivamente, porque una vez empoderada reconoce su sabiduría y se convierte en guía y mentora de jóvenes empeñados en destacar en los espacios artístico-culturales costarricenses; jóvenes creativos a los que estimuló y a quienes posicionó y apadrinó en sus proyectos hasta que aprendieron a creer en sí mismos. El buceo interior le confirió, además, la vida plena de la que escribe Peggy von Mayer porque, en su urgencia de ser, Lilia cultivó no solo su vocación de educadora y escritora, sino la resistencia para fortalecer y defender su privativo apartándose de "la actitud de la mayoría sujeta a normas estúpidas, a un tirano doméstico o foráneo" (Ramos, p. 225). En ese sentido desenmascaró a las autoridades que, en distintos períodos, la acosan y acusan, mientras ejerce de maestra y promotora cultural.

Es sugerente observar la forma en la que Lilia incorpora las denuncias, respecto a las actuaciones persecutorias de las autoridades educativas, en el Curriculum operis y no en la autobiografía, porque es precisamente su intelecto, afirmado con el cambio de nombre y con la superación del complejo de fealdad, el que desata las envidias y los acosos sobre ella. Este curriculum causa admiración, aún hoy, por las numerosas becas que ganó, los títulos obtenidos, los estudios y trabajos realizados, los premios que recibió, los libros que escribió, sus proyectos educativos, sus tertulias, etcétera; pero aunque Lilia brilló en Costa Rica y en el extranjero, causa asombro el escaso reconocimiento y difusión de sus obras pedagógicas y literarias en los espacios consagrados, pues fue ninguneada por los funcionarios que se turnaron en el poder, quienes nunca le perdonaron que una mujer desarrollara proyectos educativos trascendentales para la sociedad costarricense.

Los desplantes de Lilia frente a las autoridades eran impensables en una época en la cual las mujeres, por los escasos lugares sociales autorizados, debían reproducir el eterno femenino cultivando la sumisión, la modestia, el silencio y la pasividad. 
Pero apenas graduándose de maestra achaca a la envidia de "retrógrados ingenuos o malvados", como califica al presidente León Cortés y al ministro de educación Alejandro Aguilar Machado, el impedimento para disfrutar de una beca en Chile. Ambas autoridades urdieron, según relata, "una calumnia para evitar que yo me fuera a gozar de los honores concedidos por la Universidad de Chile [...] Cortés y Aguilar aseguraron al encargado de negocios [...] que yo había participado en una huelga del Atlántico" (Ramos, p. 227). De estos personajes recibe calificativos infamantes que la acusan de atea por ser librepensadora y de comunista porque "visitaba los hogares pobres o miserables, pues no había servicio social" (Ramos, p. 226) y son ellos, catalogados por Lilia de nazi-fascistas por su apoyo a Franco, quienes le obstruyeron la escuela de padres, uno de sus célebres proyectos.

Las denuncias de Lilia se extendieron a lo largo de su vida, como se comprueba cuando, desafiante, acusa al ministro de educación Teodoro Picado, por destituirla como maestra porque "creía que yo dañaba a mis alumnos al abogar por lecciones de educación sexual para jóvenes y padres de familia” (Ramos, 228). El desenmascaramiento va más allá cuando acusa a Luis Felipe González de apropiarse de sus ideas educativas, simulando ser el "precursor de la necesidad de impartir esas enseñanzas" (Ramos, p. 228). Maestra con vocación y enemiga acérrima del servilismo" "Lilia se atrevió a corregir en público al Secretario de Educación Luis Demetrio Tinoco, cuando este atribuyó a Martí una obra de Sarmiento, rectificación nunca perdonada y de la cual Tinoco se desquitó acusándola de comunista ante los funcionarios de la embajada de Estados Unidos, para que no le otorgaran la visa con la que saldría del país a disfrutar "de dos becas en universidades estadounidenses" (Ramos, p. 229).

Otorgada la visa se evidenció el sainete montado por las autoridades costarricenses contra Lilia quien, habituada a semejantes arbitrariedades, salió fortalecida. Según sus palabras, la "serie de obstáculos e injusticias me hizo ver que mis ideas nuevas y mi carácter firme, altivo y sincero, desconcertaban a mis jefes: yo era un reto a su atraso lamentable por neofóbicos, torpes o cobardes" (Ramos, p. 229). Las discordancias entre Lilia y las autoridades persistieron como se constata cuando 
fue destituida de su cargo de directora de la Escuela Profesional Femenina, por Otilio Ulate y el ministro de educación Virgilio Chaverri, acto que la motivó a trabajar y a estudiar en el extranjero de donde regresa con un vasto conocimiento en psicopedagogía, para comprobar que el hostigamiento no ha terminado, pues Uladislao Gámez, ministro de educación costarricense ataca sus proyectos, como lo hacen, asimismo, "José J. Trejos y Guillermo Malavassi, [...] enemigo acérrimo de los maestros" (Ramos, p. 235), quien la despide después de cuarenta y cuatro años de servicios en educación. ${ }^{6}$

En una época donde el sistema androcéntrico seguía encomendando a las mujeres las labores domésticas y la preservación de la especie, la mujer que no se plegara a tal prescripción y la desafiara, era denigrada, por estar vigentes cantilenas como la del filósofo y rector de la Universidad de Salamanca Miguel de Unamuno, en la cual amonestaba a una joven que le expuso su deseo de ser escritora. Según Unamuno la lengua literaria era "un instrumento hecho por hombres y para hombres [...] A la mujer está encomendada principalmente la perpetuación del linaje humano [...] y al hombre la civilización” (Citado por Freixas, 2000, p. 123).7 Desde esa perspectiva era impensable que en la sociedad josefina de la que habían huido hacia México algunas escritoras que querían universalizar su escritura, una mujer alterara el orden de las cosas, desafiando el lugar concertado para lo femenino.

Llamando a las cosas y a los funcionarios por su nombre, Lilia enfrentó todas las infamias y con el sistema en contra, descubrió su propio espacio para pensar, escribir y crear, sin abandonar su patria, excepto cuando estudió o desarrolló proyectos educativos en otros países donde fue ampliamente reconocida. Sus estudios en pedagogía y psicología, el intercambio con sus pares y su vocación de maestra la hicieron conocedora de las deficiencias educativas costarricenses, anomalías que se propuso solucionar sin que su resistencia declinara, pese a los hostigamientos de las autoridades, sirviéndole de incentivo cada embate, para poner en ejecución sus nuevas ideas (Ramos, p. 226). ${ }^{8}$ 
La estrategia de Lilia para contar-se en Fulgores en mi ocaso es seductora, pues se parapeta tras el recuento-recuerdo de numerosos intelectuales nacionales y foráneos, con los cuales se relacionó a través del tiempo. Aunque algunos fragmentos de su vida van quedando desperdigados, mientras narra la de sus luminares, su autobiografía de cinco páginas, incluida al final del libro y como al descuido, la enriquece con los once folios de su curriculum operis, documento donde expone sus estudios, sus experiencias profesionales, su extensa obra literaria, sus luchas contra las autoridades educativas y sus propuestas referentes a la enseñanza-aprendizaje en las escuelas costarricenses.

El posicionamiento adquirido por Lilia, al repudiar el nombre de la abuela, trasciende cada vez que se regodea con su nombre, especialmente en el curriculum operis donde incluye un amplio muestrario de homenajes en los cuales sobresale su nombre, como la dedicatoria de Max Jiménez que expresa: "Lilia Ramos. Ud. Es traslúcida. Ud. Es diáfana. Ud. Es uno de mis días jubilosos en mi existencia” (Ramos, p. 48). En otro fragmento registra la deferencia de Juan Rulfo cuando le autografía Pedro Páramo y El llano en llamas y que dice "Para la gran amiga y embajadora de la cultura centroamericana, Lilia Ramos” (Ramos, p. 235), asimismo el homenaje de Hernán Elizondo en Memorias de un pobre diablo: “A la culta profesora Lilia Ramos, como parte del tributo que a su inmensa labor espiritual le debemos los costarricenses". Entre las dedicatorias destaca, también la escrita por Carmen Naranjo en la obra Los perros no ladraron: "A Lilia Ramos, a un camino claro" (Ramos, p. 236) y la de Rima de Valbona que termina su obra Las sombras que perseguimos, agradeciendo "A Lilia Ramos, guía y apoyo de la juventud de mi tierra. Con cariño y devoción” (Ramos, p. 236); homenajes a los que se suma el de Alfonso Chase cuando le dedica el libro Patria: "Lilia Ramos, este libro es suyo. Porque desde siempre me enseñó a amar la memoria” (Ramos, p. 237).

Además del regocijo con su nombre, repetido y recreado en las voces de amigos y discípulos que la elogian en las dedicatorias, la conquista de éste le proporcionó 
a Lilia la firmeza para desafiar el complejo de "fealdad", como se aprecia en la reconciliación con su imagen al incluir en el libro Fulgores en mi ocaso, numerosas fotografías de sus viajes, de distinciones recibidas, de sus lugares de estudio, de sus compañeros y amigos. Especie de homenaje amoroso a quienes la enriquecieron espiritualmente y la estimularon a resplandecer, el libro reúne a una serie de personajes ilustres entre los que sobresale el maestro Carlos Gagini, junto con Yolanda Oreamuno y José Basileo Acuña, amigo, poeta y pionero de la psicología profunda, al que Lilia describe como "uno de los hombres más claros que he hallado en mi camino de luces" (Ramos, p. 65). ${ }^{9}$

Entre los escritores foráneos destaca Joâo Guimarâes Rosa, escritor del que Lilia escucha elogiosos comentarios en una plática que sostuviera con el mexicano Juan Rulfo. Admiradora de ambos autores, Guimarâes se lleva todas las distinciones pues, conocida su obra, lo llama demiurgo y lo nombra: "Un himalaya ser humano. Un Himalaya autor. Un sujeto íntegro en ascenso continuo sin perder jamás su índole terrícola" (Ramos, p. 125). La pasión de Lilia por Guimarâes es tan genuina, que la registra en una foto donde muestra la más radiante de sus sonrisas, mientras el demiurgo seducido la abraza.

La empatía entre ambos se vislumbra en las interrogantes que Lilia se plantea en su presencia: “¿Qué le da a Joâo Guimarâes Rosa un nimbo deslumbrador? ¿Su piedad eviterna transformada en actos generosos? ¿Su cordialidad? ¿Su placidez comunicativa? ¿Su conversación amena y sabia? ¿La excelsitud de su obra? (Ramos, p. 125), agregando a continuación: “¡Es tan fuerte el resplandor Joâo Guimarâes Rosa, que eclipsa otros soles de primera magnitud! Brilla mucho, a pesar de él en su afán de nivelarse elevando a los demás” (Ramos, p. 123) Todas estas interrogantes y comentarios referentes a Joâo Guimarâes Rosa podrían haberse hecho, cambiando el nombre del escritor brasileño por el de Lilia Ramos, quienes conocieron a esta mujer deslumbradora por su sabiduría. 
La infancia es un lugar al que no se puede regresar [...] pero del que en realidad nunca se sale.

(La ridícula idea de no volver a verte, 2013)

Este acercamiento a la Autobiografía y al Curriculum operis vislumbra la importancia de llamarse Lilia, para aquella niña que albergaba grandes sueños, desde que conquistó su derecho a autonombrarse, momento a partir del cual adquiere la firmeza para combatir otros demonios que la perseguían, como el complejo de fealdad, obsesión que logró dominar al descubrirse artífice de sí misma. Con un curriculum inimaginable y venciendo todo tipo de obstáculos para beneficio de la cultura costarricense, Lilia Ramos se ocupó de proyectos trascendentales, haciendo de su profesión un credo y de la resistencia una forma de vida.

En su urgencia de ser y consciente de su privativo diáfano y robusto, Lilia no perdió tiempo en escuchar los halagos de los otros, porque se dedicó a cultivar su intelecto. En una época donde la mujer debía sacrificar sus propios deseos para cumplir el de sus padres-novios-maridos-hijos, Lilia realizó sus aspiraciones personales: fue maestra, estudió psicología, ayudó a los demás a desarrollar sus potencialidades, ensayó todo tipo de proyectos para resolver las necesidades educativas costarricenses, prodigó conocimiento, apadrinó a cuantos la requirieron; en síntesis fue una humanista que vivió y amó la vida plena y se empeñó en ir más allá de su propia vida para estar en la vida de los otros, como sugiriera la filósofa española María Zambrano.

Es probable que si Lilia hubiera sido una beldad la actuación de las autoridades hubiera estado plagada de adulaciones, como la simulada por el narrador de la novela de Sergio Ramírez La fugitiva, que finge buscar a alguien más en la habitación, "como una cortesía improvisada", cuando Lilia (Marina Carmona) 
se autodenomina la fea de la historia ${ }^{10}$. Sin desvelarse por su belleza física Lilia pudo elaborar, desarrollar y defender todos sus proyectos, con argumentos actualizados y despolitizados, sin esperar halagos por ser mujer. Es presumible que Lilia no hubiera desentonado siendo únicamente maestra, pero intrusa en el mundo masculino, desde cualquier ángulo que se mire, se atrevió a pensar de igual a igual al varón, a irrumpir en los espacios consagrados y a basar su atractivo en el intelecto, acciones imperdonables en una sociedad tradicional.

La obra de Lilia Ramos es una veta inexplorada que espera ser descubierta y reconocida en las Facultades de Letras, de Educación y de Psicología de la Universidad de Costa Rica, espacios donde la humanista debería brillar, porque Lilia Ramos es merecedora de una cátedra en alguna de estas Escuelas, por sus aportaciones a estas disciplinas académicas. 
1. En el libro Donde renace la esperanza, Lilia Ramos reconoce que, "Los complejos bien estimulados por los guías en la educación del niño y del adolescente, siempre dan frutos de la más alta calidad" (Pág. 168). Recordemos que Ramos tuvo a los mejores maestros; entre ellos Clorito Picado, Anastasio Alfaro y al ilustre Carlos Gagini, mentor al que alaba en Fulgores en mi ocaso, por sabio y dadivoso, págs. 28-30.

2. Mientras es terapeuta en el Institute of Living, donde estaba el Hospital Neuro-psiquiátrico, Lilia se ríe de su "fealdad" cuando, de broma, le pide a una internada le halle un marido si la sigue llamando Mrs. Ramos, a lo cual le responde la enferma: “_En qué apuro me ha puesto! No he podido conseguir para mí, joven y linda... Su risa completó el pensamiento”. Pág. 54 del libro Donde renace la esperanza.

3. En Limón su madre adquiere el paludismo, enfermedad de la que muere estando embarazada y Lilia, con catorce años, pasa a vivir con sus hermanos en la casa de sus tías, mientras el padre regresó a "Puerto Limón donde trabajaba en una compañía estadounidense muy feroz" (Ramos, 224) que le robó la patente de su invento. Nombrado cónsul en México desaparece sin que se sepa nada más de él, dejando a sus hijos en la miseria.

4. En el libro Fulgores en mi ocaso Lilia reconoce su pertenencia a estos grupos étnicos cuando escribe sobre el destacado escultor Juan Manuel Sánchez y afirma "Juan Manuel y yo somos buenos ejemplos de los aborígenes costarricenses" (Ramos, 37). Además lo llama varias veces indio retador, como retadora ella y alaba la lealtad de Sánchez "a su herencia primigenia" (Ramos, 38).

5. Véase la contraportada del libro Donde renace la esperanza, de Lilia Ramos, en la que Carlos Gagini se expresa así, sobre su discípula: "Entre los centenares de 
jóvenes a cuya educación he tenido el honor de contribuir, escasamente habrá una docena que iguale en inteligencia, aplicación y esfuerzo a Lilia Ramos. Consagrada en cuerpo y alma al estudio, ávida de saber, ha cultivado todas las ciencias y las artes. No hay materia, por abstrusa que sea, a la que no haya dedicado una parte de su tiempo. Pero hay algo en la Srta. Ramos aún más notable que su claro talento, que su sabiduría y que su admirable perseverancia: la integridad de su carácter. Enérgica y altiva, enemiga acérrima del servilismo, jamás dobla el cuello a las injusticias y protesta contra la tiranía, la imposición y la maldad".

6. Es sugerente observar que, mientras las autobiógrafas centroamericanas que escriben durante el mismo período al que se refiere Lilia denuncian las tropelías cometidas contra los pueblos de la región, por dictadores como Ubico, Hernández Martínez, Carías, Somoza y otros, Lilia acusa a las autoridades costarricenses de cerrarle todos los caminos a sus proyectos educativos. Véase el primer capítulo del libro Escrituras del yo femenino en Centroamérica 19402002, de Teresa Fallas, para conocer sobre las autobiógrafas de la región.

7. Freixas toma la cita de "A una aspirante a escritora", Soliloquios y conversaciones, Obras completas, tomo III.

8. La enseñanza de la sexualidad ha sido un tema controversial en Costa Rica por el protagonismo de la iglesia católica en este tema, aunque es el sector menos apto para la enseñanza de esta. No es sino hasta el 2013 que el ministro de educación ha podido implementar lecciones de educación sexual en algunos colegios a modo de experimento, después de una ardua lucha con sectores de la iglesia católica y de otras denominaciones.

9. Además reconoce en Fulgores en mi ocaso a escritores a los que estimuló como Julieta Pinto, Daniel Gallegos, Rima de Vallbona y a escritoras foráneas entre las cuales destacan Alaíde Foppa, Argentina Díaz Lozano, etc. 
La importancia de llamarse Lilia

10. Véase la novela La fugitiva, donde Ramírez recrea a Yolanda Oreamuno a través de las voces de algunas de sus amigas, entre ellas Lilia, a la que el escritor nicaragüense no aprecia, en su vasta dimensión, haciendo una caricatura y remedando prejuicios y estereotipos acerca de ella (Ramírez, 138). Tampoco respeta el amplio léxico de la escritora cuando comenta que los vocablos utilizados por Lilia han caído en desuso "y otros debieron ser raros, como conservados en formol, aún en su tiempo" (Ramírez, 136). 
Butler, Judith. (2004). Lenguaje, poder e identidad. Madrid, Síntesis.

Calvo, Yadira. "Lilia Ramos: La memoria en el espejo". En Gold, Janet. (Comp.) Volver a imaginarlas, Tegucigalpa: Guaymuras.

(1999) "Lilia Ramos, escritora y maestra". En Revista

iberoamericana. Disponible en: http://revista-iberoamericana.pitt.edu/ojs/index. php/Iberoamericana/article/download/4327/4495

Eco, Umberto. (2013). Historia de la fealdad. China, Debolsillo.

Demetrio, Duccio. (1999) Escribirse: La autobiografía como curación de uno mismo. Barcelona: Paidós.

De Valbona, Rima. "Yolanda Oreamuno en el recuerdo de Lilia Ramos". En Gold, Janet (Comp.) (1998). Volver a imaginarlas, Tegucigalpa: Guaymuras.

Eco, Umberto. (1997). ¿En qué creen los que no creen? México: Taurus.

Fallas, Teresa. (2013). Escrituras del yo femenino en Centroamérica 1940-2002. San José: Editorial Universidad de Costa Rica.

Montero, Rosa (2013). La ridícula idea de no volver a verte. Barcelona, Seix Barral.

Ramos, Lilia. (1978). Fulgores en mi ocaso. San José, editorial Costa Rica. (1963). Donde renace la esperanza. San José, ediciones Elite.

Von Mayer, Peggy. “La vida plena de Lilia Ramos”. En Áncora, La Nación, 23 de junio de 2013. 